\title{
Development of nimesulide analogues as dual tubulin and HSP27 inhibitor for treating female cancers
}

\author{
Laila J. Alhadad ${ }^{\text {a, }}$, Gamaleldin I. Harisa ${ }^{\text {b,c,d }}$, Fars K. Alanazi ${ }^{\text {b,c }}$
}

${ }^{a}$ Department of Chemistry, College of Science, Kuwait University, Safat, Kuwait

${ }^{\mathrm{b}}$ Kayyali Chair for Pharmaceutical Industry, College of Pharmacy, King Saud University, Riyadh, Saudi Arabia

${ }^{c}$ Department of Pharmaceutics, College of Pharmacy, King Saud University, Riyadh, Saudi Arabia

${ }^{\mathrm{d}}$ Department of Biochemistry, College of Pharmacy, Al-Azhar University, Nasr City, Cairo, Egypt

\section{Corresponding author}

*Laila.alhadad@ku.edu.kw

Department of Chemistry,

Faculty of Science, Kuwait University,

P.O. Box 5969 Safat 13060 Kuwait 


\begin{abstract}
Tubulin and heat shock protein 27 (HSP27) are up-regulated in cancer cells, and play a critical role in cell division, and proliferation. Therefore, they are targets for discovery of anticancer therapy. The objective of this study is to design, characterize, and biologically evaluate the nimesulide analogues to combat female cancer such as ovarian cancer, and breast cancer. Herein, the nimesulide analogues are designed to target both tubulin and HSP27 functions. Ovarian cancer (SKOV3) and breast cancer (SKBR3) cell lines were used as surrogate models to test the nimesulide analogs biological activities using MTT assay. In the present study, four nimesulide analogues were designed, synthesized and the chemical structures were with the biological evaluation were studied. The synthesized agents were characterized by ${ }^{1} \mathrm{H}-\mathrm{NMR},{ }^{13} \mathrm{C}-\mathrm{NMR}$, the molecular weight was confirmed using GC-MS technique, and melting point. Besides, the agent L4 structure was confirmed using X-ray crystallographic analysis. The present data revealed that nimesulide analogs have potent anticancer activity against SKOV3and SKBR3 cell lines. The $\mathrm{IC}_{50}$ values for both SKOV3 and SKBR3 cell lines treated with the agents showed a potent cell growth inhibition range of $0.23-2.02 \mu \mathrm{M}$ and $0.50-3.73 \mu \mathrm{M}$ respectively. In conclusion, the designed nimesulide analogues can target both tubulins, and HSP27 concurrently, and they are promising agents as future chemotherapy female cancers.
\end{abstract}

Keywords: Anticancer, Tubulin, HSP27, Nimesulide, SKOV3, SKBR3.

\begin{abstract}
Abbreviations
MTT, 3-(4,5-Dimethylthiazol-2-yl)-2,5-diphenyltetrazolium bromide; IC 50 , Inhibitor concentration when reduced by half; PBS, phosphate buffer saline; FBS, Fetal Bovin serum; PBS, Phosphate buffer saline; NFDM, non-fat dry milk; $\mathrm{IC}_{50}$, Inhibitor concentration when reduced by half; DMSO, dimethyl sulfoxide.
\end{abstract}




\section{Introduction}

The microtubules control many vital functions in the cells such as cell division, cell movement cellular trafficking, and many other biological functions. The main structural component of microtubules is the protein tubulin. ${ }^{1-2}$ Given the importance of tubulin, it is potentially targeted for the discovery of natural and synthetic agents in cancer treatment. ${ }^{1-2}$ Tubulin is a highly dynamic structured protein and is involved in cell division, movement, intracellular trafficking, maintenance, and mitosis. Alpha and beta polypeptide subunits form tubulin the rigid cylindershaped protofilament. ${ }^{1-2}$ Thirteen protofilaments form a straw-shaped filament known as microtubules, which is a major component of the cytoskeleton and forms the spindle structure that appears during cell division. ${ }^{1-2}$ Microtubule dynamics rely on the $\alpha$ - $\beta$-tubulin dimer's hydrolysis that binds $\alpha$ to GTP (minus end) and $\beta$ to GDP (plus end). This cycle is important for microtubule dynamic stability and cell division. ${ }^{1-2}$ The rapid growth of cancer cells leads to their high dependence on tubulin polymerization/ depolymerization, which makes tubulin a highly attractive target for anticancer drug design. ${ }^{1-2}$ Several studies reported that microtubules inhibitor as anticancer agents, paclitaxel is an example of a drug used clinically for cancer treatment. It binds to tubulin and inhibits the polymerization/depolymerization process and causes mitotic arrest and then cancer cell death. However, after a good response to the initial treatments, most of the approved drugs become less effective due to the development of drug resistance in patients. ${ }^{2,3}$ Therefore, further studies are required to discover anticancer agents to inhibit microtubules polymerization with minimal side effects.

Additionally, heat shock protein 27 (HSP27) is a small protein with $27 \mathrm{kDa}$ that facilitates the refolding of the damaged proteins. ${ }^{4,5}$ HSP27 responds to heat shock and cellular stress conditions when face carcinogens and functions as an anti-apoptotic agent. ${ }^{6-16}$ HSP27 is found to be up-regulated in many cancers including liver, bladder, ${ }^{17}$ pancreases, ovarian, and breast. ${ }^{13-18}$ 
The previous reported that targeting HSP27 using antisense oligonucleotide -427 decreases HSP27 expression. Also, antisense oligonucleotide - 427 in combination with chloroquine has been reported to decrease prostate cancer xenograft; herein, inhibition of HSP27 is a promising target in cancer therapy. ${ }^{17,19-21}$

Although the current clinically used anticancer drugs showed great benefits in female cancer treatments, there is a requirement for the development of novel anticancer drugs with enhanced pharmacological activity and ideal therapeutic index ${ }^{10,19}$. In the previous reports, the scientists established many potent agents that targeted HSP27 function and showed cytotoxicity against ovarian cancer cell lines. ${ }^{22}$ Based on these dual reliable protein biomarkers ${ }^{15}$ tubulin and HSP27. ${ }^{8,9}$ In the last years, new agents were developed with dual targeting both tubulin and HSP27 proteins for breast cancer treatment using chaperonin and tubulin polymerization inhibition assays. ${ }^{23,24}$ Recently, HSP27-HER2 dual inhibitor cholesterol conjugate was studied in our study using western blotting, and the prepared inhibitor can inhibit ovarian cancer cell lines. ${ }^{25}$

Cyclooxygenase-2 is frequently expressed in many types of cancers exerting a pleiotropic and multifaceted role promotion of carcinogenesis and cancer cell resistance. ${ }^{26}$ Nimesulide is considered a selective cyclooxygenase- 2 inhibitor. In the last years, nimesulide was reported as an antitumor agent, besides its roles as an anti-inflammatory, pain killer, and antipyretic action. ${ }^{27-28}$ Thus, numerous works were achieved on the nimesulide skeleton to obtain selective cyclooxygenase-2 inhibitors with potential antitumor action. ${ }^{27-28}$ Further studies are required to address this assumption. Therefore, the current work aimed to develop novel, and potential compounds based on nimesulide structure figure 1 with targeting the ability to tubulin and HSP27 concurrently. The cytotoxicity of the design anticancer agent against both ovarian and breast cancer cell lines was investigated as a surrogate model for female cancers. The structure-activity 
relationship was applied to the nimesulide drug lead structure to obtain the analogs by keeping the important positions a, b, c fixed, and changing only position d as shown in Figure 2.<smiles>CS(=O)(=O)Nc1ccc([N+](=O)[O-])cc1Oc1ccccc1</smiles>

Figure 1: Nimesulide lead structure for the drug design.

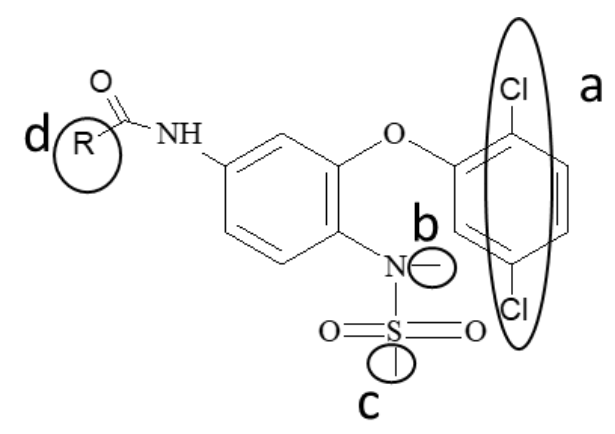

Figure 2: Structure-activity relationship to obtain nimesulide analogs.

\section{Results and discussion}

The main structural component of microtubules is the protein tubulin. Tubulin is a potential target for the discovery of natural and synthetic agents in cancer treatment. ${ }^{29}$ Moreover, HSP27 is found to be up-regulated in many cancers, and the inhibition of HSP27 was reported as a promising target in cancer therapy. ${ }^{13-21}$ In the last year, nimesulide was reported as an antitumor agent ${ }^{27-28}$, further studies are required to address this issue. Therefore, in the present study, four nimesulide analogues were designed, synthesized and their chemical structures were elucidated and studied. The 
synthesized agents were characterized by ${ }^{1} \mathrm{H}-\mathrm{NMR},{ }^{13} \mathrm{C}-\mathrm{NMR}$, the molecular weight was confirmed using GC-MS technique, and melting point. Also, agent L4 structure was confirmed using X-ray crystallographic analysis. Furthermore, the dual tubulin and HSP27 inhibition were investigated, besides the cytotoxicity against both ovarian and breast cancer cell lines.

\subsection{Chemistry}

According to the synthetic route shown in scheme 1, four nimesulide analogs were designed, synthesized and the chemical structures were shown in Table 1 with the biological evaluation results. The synthesized agents were characterized by ${ }^{1} \mathrm{H}-\mathrm{NMR},{ }^{13} \mathrm{C}-\mathrm{NMR}$, the molecular weight was confirmed using GC-MS technique, and melting point. Besides, the agent L4 structure was confirmed using X-ray crystallographic analysis as shown in Figure 4.

\subsection{Anticancer activities evaluation of agents targeting dual proteins tubulin and HSP27 in women} cancer cell lines using MTT assay

Dual protein inhibitors were developed and evaluated for their potency in a panel of SKOV3 and SKBR3 cell lines using MTT assay and the $\mathrm{IC}_{50}$ values were calculated and summarized in Table 1. The cells were seeded at a concentration of $25 \mathrm{mg} / \mathrm{L}$, and most of the agents showed desired anticancer activity. The data revealed that SKOV3 cell line adapted cell growth inhibition ranged from $0.20 \mu \mathrm{M}$ to $2.02 \mu \mathrm{M}$. While SKBR3 cell line showed cell growth inhibition ranges from 0.50 $\mu \mathrm{M}$ to $3.70 \mu \mathrm{M}$. In sum, the data analysis of the preliminary bioassay indicated that the synthetic agents had potent anti-cancer activity and targeted dual proteins in both cell lines. 
7

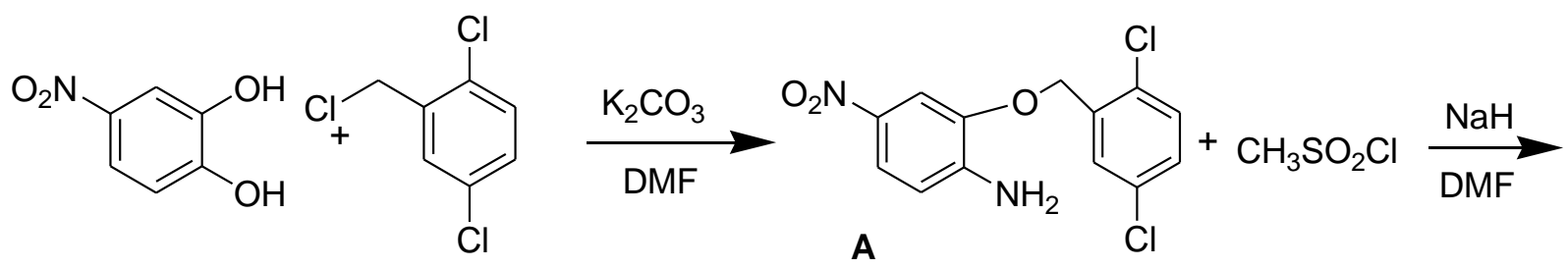

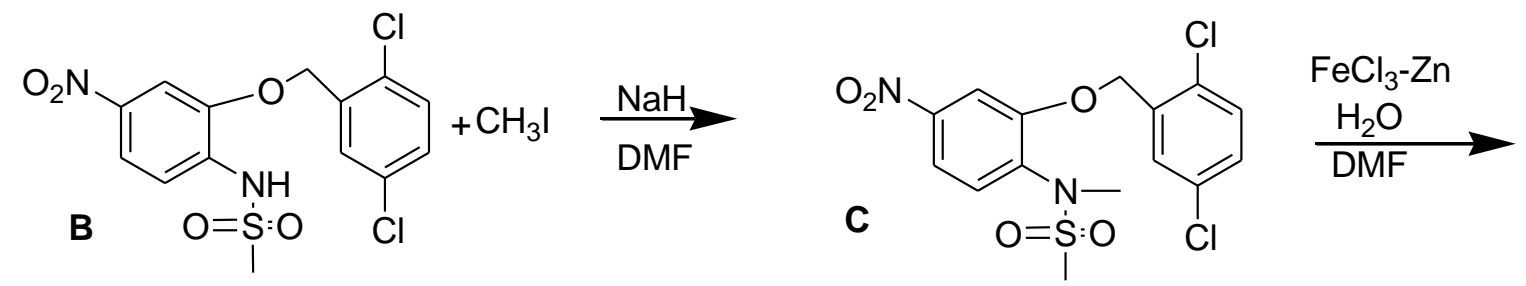<smiles>CN(c1ccc(N)cc1OCc1cc(Cl)ccc1Cl)S(C)(=O)=O</smiles><smiles>C[C@H](O)[C@@H](O)[Mg]</smiles><smiles>[R]C(=O)Nc1ccc(N(C)C)c(OCc2cc(Cl)ccc2Cl)c1</smiles>

(d position) $\mathrm{R}=2,3,4,5$

(2)<smiles>COc1ccc(C(N)=O)cc1</smiles>

(3)<smiles>COc1cccc(C(N)=O)c1OC</smiles>

(4)<smiles>NC(=O)c1ccc(I)cc1</smiles>

(5)<smiles>NC(=O)c1cccc2ccccc12</smiles>

\section{4-methoxy benzamide}

dimethoxy benzamide

4-iodo benzamide

naphthylamide

Scheme 1: Reaction pathways synthesis procedures to obtain agents L 2-5, the structural difference is in position d. 


\section{Table 1}

Chemical structures of nimesulide analogs with the anticancer biological activities

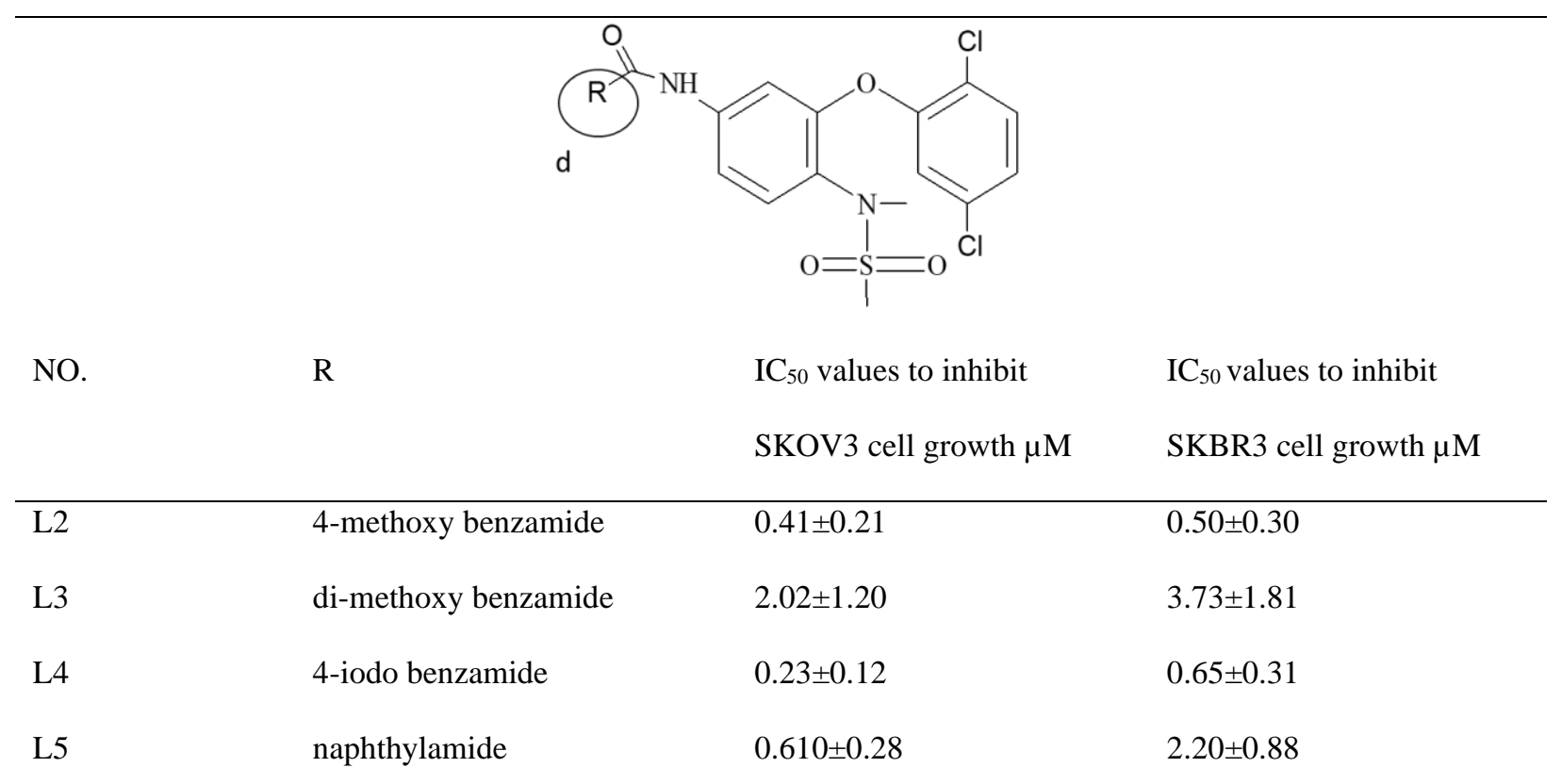

$\overline{\text { Chemical structure and anticancer activities evaluation of ovarian cancer (SKOV3) and breast cancer (SKBR3) cell }}$ lines.

\subsection{Targeting dual proteins in SKOV3 and SKBR3 cell lines using western blot assay}

Western blot analysis was performed, and total cell lysates for SKOV3 and SKBR3 cell lines were extracted and treated with DMSO and separated by SDS-PAGE then transferred into nitrocellulose membrane. The membrane was blocked for one hour with NFDM, followed by being probed with the primary and secondary antibodies targeting HSP27 protein and tubulin respectively for one hour each. B-actin was used as our housekeeping control as depicted in Figure 3. The data revealed that two cell lines expressing HSP27 protein and tubulin. 


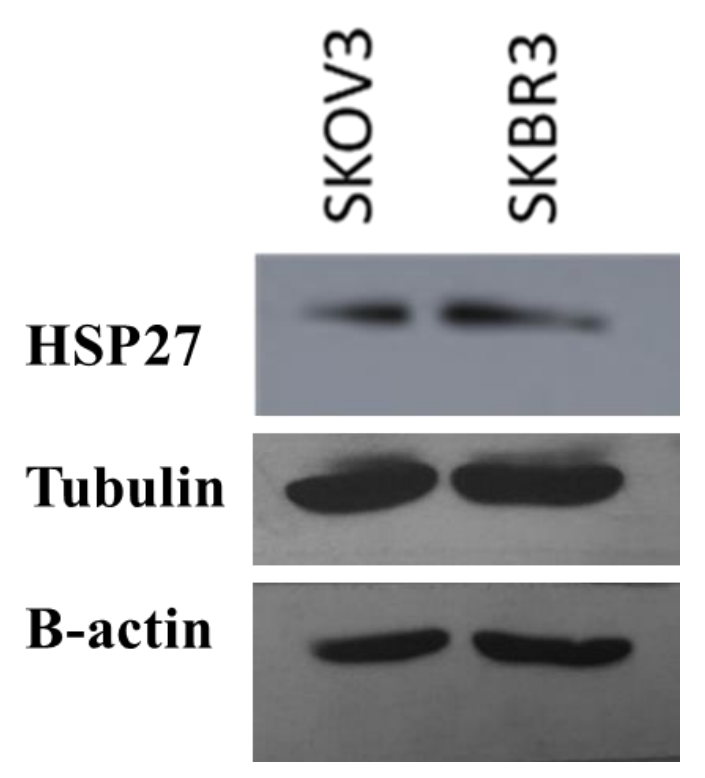

Figure 3: SKOV3 and SKBR3 cells were treated with DMSO for $24 \mathrm{hr}$. Levels of the dual proteins were analyzed by western blot of cell extracts with specific antibodies as described in the experimental section.

The results of the present study are in agreement with several previous studies reported that nimesulide analogs have anti-cancer properties. ${ }^{27,28}$ Particularly, cyclooxygenase-2 is frequently expressed in many types of cancers, and promote the carcinogenesis and resistance of cancer cells to therapy. ${ }^{26}$ However, the link between cyclooxygenase- 2 inhibition and anticancer activity of nimesulide and its analogues is not clearly established and not fully understood. ${ }^{27,28}$ In general, nimesulide and their analogues revealed both anticancer cyclooxygenase- 2 dependent and independent mechanisms. ${ }^{27,28}$ In the present study, dual tubulin, and $\mathrm{HSP}^{27}$ inhibition by the developed nimesulide analogues might responsible for the cytotoxic effect against SKOV3 and SKBR3 cell lines. In this context, it has been reported that the disruption of microtubules functions induces cell cycle arrest and cell death. ${ }^{29}$ As well, a previous study documented that, the dual inhibition of HSP27-HER2 can inhibit ovarian cancer cell lines. ${ }^{25}$ Further studies are required for the development of new nimesulide analogues with improved anticancer potency. In addition, the 
confirmation of the anticancer effects of developed nimesulide analogues required additional in vivo studies including tumor-bearing female animals.

\section{Experimental section}

\subsection{Materials and methods}

Nimesulide analogs were synthesized in our laboratory. All chemicals and solvents used for the synthesis of compounds were commercially available and were used directly without the need for any preparation. All chemical spectral analysis was done at Kuwait University Research Sector Project Unit - RSPU. TLC was performed using Polygram SIL G/UV 254 TLC plates and visualized under ultraviolet light at 254-and 350nm, with hexane/ethyl acetate solvent. Column chromatography was performed using silica gel $60 \mathrm{~A}$ of mesh size $40-60 \mu \mathrm{m} .{ }^{1} \mathrm{H}$ and ${ }^{13} \mathrm{C}$ nuclear magnetic resonance (NMR) spectra were obtained using NMR spectrophotometer Bruker, DPX 600 at $600 \mathrm{MHz}$ and $150 \mathrm{MHz}$ in DMSO and in $\mathrm{CDCL}_{3}$ respectively. Mass spectra were acquired using a GC- MS DFS - Thermo spectrometer. IR spectra were obtained with a Jasco 6300 FTIR. Determination of the melting point spectra done using a differential scanning calorimeter- Netzsch DSC 204 F1 Phoenix. The X-ray structure for Agent L4 was refined using the Bruker SHELXTL software package.

\subsection{Synthesis}

\subsubsection{General procedure for the synthesis of compound L 2-5}

2-Amino-5-nitrophenol (1 eq.) was used as our starting material and was mixed with $\mathrm{K}_{2} \mathrm{CO}_{3}$ (1 eq.) and 2,5-dichlorobenzyl chloride (1 eq.) in DMF to obtain compound A. In the next step, both sodium hydride (5 eq.) and methane sulfonyl chloride (1 eq.) was added to compound A (1 eq.) in dry DMF at room temperature and the reaction mixture was left overnight to obtain compound B. This was followed by a methylation step in presence of methyl iodide and sodium hydride and 
DMF to produce compound $\mathrm{C}$. Then, it was reduced in the presence of $\mathrm{Zn}$ (10 eq.), $\mathrm{FeCl}_{3}$ (4 eq.), $\mathrm{DMF}$, and water to reduce the nitro group in compound $\mathrm{C}$ to an amine group and obtain compound D. Then, different moieties such as (1) 4-methoxybenzamide (2) 3,4-dimethoxybenzamide (3) 4iodobenzamide (4) naphthylamide were added with (1 eq.), $\mathrm{K}_{2} \mathrm{CO}_{3}$ (1 eq.), and 1:4 dioxane were added to compound D (1 eq.) to obtain the final compounds L2-5, which are our dual proteins inhibitors. The synthesis steps were carried out at room temperature. Water was used to quench all the reactions' steps. Reaction steps were tested by TLC to check the end-point. Compounds were purified by column chromatography.

3.2.2 Synthesis of N-(3-((2,5-dichlorobenzyl)oxy)-4-(N-methylmethylsulfonamido)phenyl)-4methoxybenzamide (L2)

White product, yield 70\%; m.p. $165-167^{\circ} \mathrm{C} . \mathrm{IR}\left(\mathrm{cm}^{-1}\right): 3360(\mathrm{NH}), 1741(\mathrm{CO}) ;{ }^{1} \mathrm{H}$ NMR $\left(\mathrm{CDCl}_{3}\right)$ : $\delta, \mathrm{ppm}=2.86\left(\mathrm{~s}, 3 \mathrm{H}, \mathrm{CH}_{3}\right), 3.26\left(\mathrm{~s}, 3 \mathrm{H}, \mathrm{CH}_{3}\right), 3.90\left(\mathrm{~s}, 3 \mathrm{H}, \mathrm{OCH}_{3}\right), 5.20\left(\mathrm{~s}, 2 \mathrm{H}, \mathrm{CH}_{2}\right), 5.20-7.95$ $\left(\mathrm{m}, 11 \mathrm{H}, \mathrm{Ar}-\mathrm{H}, \mathrm{NH}, \mathrm{D}_{2} \mathrm{O}\right.$ exchangeable $) ;{ }^{13} \mathrm{C} \mathrm{NMR}\left(\mathrm{CDCl}_{3}\right): \delta, \mathrm{ppm}=165.55,163.01,155.39$, $139.92,135.55,133.36,132.84,131.82,131.09(2 \mathrm{C}), 130.07,129.93,129.18(2 \mathrm{C}), 126.81,125.07$, 114.34, 112.74, 105.17, 67.66, 55.74, 38.37, 38.11. $\mathrm{C}_{23} \mathrm{H}_{23} \mathrm{Cl}_{2} \mathrm{~N}_{2} \mathrm{O}_{5} \mathrm{~S}$ MS: $m / z$ (\%) calculated 209.07; found, $508\left(\mathrm{M}^{+}, \mathrm{H}^{+}, 50\right), 429$ (70), 270 (5), 158 (10), 135 (100), 92 (10), 77 (10).

3.2.3 Synthesis of N-(3-((2,5-dichlorobenzyl)oxy)-4-(N-methylmethylsulfonamido)phenyl)-3,4dimethoxybenzamide (L3)

White product, yield 70\%; m.p. $191-193^{\circ} \mathrm{C} . \mathrm{IR}\left(\mathrm{cm}^{-1}\right): 3347(\mathrm{NH}), 1741(\mathrm{CO}) ;{ }^{1} \mathrm{H} \mathrm{NMR}\left(\mathrm{CDCl}_{3}\right)$ : $\delta, \mathrm{ppm}=2.86\left(\mathrm{~s}, 3 \mathrm{H}, \mathrm{CH}_{3}\right), 3.26\left(\mathrm{~s}, 3 \mathrm{H}, \mathrm{CH}_{3}\right), 3.97\left(\mathrm{~s}, 3 \mathrm{H}, \mathrm{OCH}_{3}\right), 3.98\left(\mathrm{~s}, 3 \mathrm{H}, \mathrm{OCH}_{3}\right), 5.20(\mathrm{~s}$, $\left.2 \mathrm{H}, \mathrm{CH}_{2}\right), 6.90-7.96\left(\mathrm{~m}, 10 \mathrm{H}, \mathrm{Ar}-\mathrm{H}, \mathrm{NH}, \mathrm{D}_{2} \mathrm{O}\right.$ exchangeable $) ;{ }^{13} \mathrm{C} \mathrm{NMR}\left(\mathrm{CDCl}_{3}\right): \delta, \mathrm{ppm}=165.59$, $155.42,152.66,149.60,139.87,135.53,133.38,132.85,131.81,131.10,130.09,129.92,127.19$, $125.14, \quad 119.69, \quad 112.73, \quad 110.94, \quad 110.62, \quad 105.15, \quad 67.65, \quad 67.32, \quad 56.35, \quad 38.40, \quad 38.11$. 
$\mathrm{C}_{24} \mathrm{H}_{25} \mathrm{Cl}_{2} \mathrm{~N}_{2} \mathrm{O}_{6} \mathrm{~S}$ MS: $m / z$ (\%) calculated 539.08; found, $538\left(\mathrm{M}^{+}, \mathrm{H}^{+}, 30\right), 459$ (30), 165 (100), $137(5), 77(5)$.

3.2.4 Synthesis of N-(3-((2,5-dichlorobenzyl)oxy)-4-(N-methylmethylsulfonamido)phenyl)-4iodobenzamide (LA)

White product, yield 75\%; m.p. $210-212^{\circ} \mathrm{C} . \mathrm{IR}\left(\mathrm{cm}^{-1}\right): 3335(\mathrm{NH}), 1741(\mathrm{CO}) ;{ }^{1} \mathrm{H} \mathrm{NMR}\left(\mathrm{CDCl}_{3}\right)$ : $\delta, \mathrm{ppm}=2.88\left(\mathrm{~s}, 3 \mathrm{H}, \mathrm{CH}_{3}\right), 3.26\left(\mathrm{~s}, 3 \mathrm{H}, \mathrm{CH}_{3}\right), 5.12\left(\mathrm{~s}, 2 \mathrm{H}, \mathrm{CH}_{2}\right), 6.94-7.87(\mathrm{~m}, 10 \mathrm{H}, \mathrm{Ar}-\mathrm{H}) 8.09$ (br, 1H, NH, $\mathrm{D}_{2} \mathrm{O}$ exchangeable); ${ }^{13} \mathrm{C} \mathrm{NMR}\left(\mathrm{CDCl}_{3}\right): \delta, \mathrm{ppm}=165.31,155.36,139.57,138.31$ (2C), 135.47, 133.98, 133.40, 132.65, 131.64, 131.06, 130.06, 129.77, 128.90 (2C), 125.37, 113.06, 105.39, 99.55, 67.58, 38.47, 38.14. $\mathrm{C}_{22} \mathrm{H}_{20} \mathrm{Cl}_{2} \mathrm{~N}_{2} \mathrm{O}_{4} \mathrm{~S}$ MS: $m / z(\%)$ calculated 604.96; found $603.9\left(\mathrm{M}^{+}, \mathrm{H}^{+}, 10\right), 524$ (100), 365 (10), 230 (80), 202 (20), 158 (30), 135 (5), 104 (10), 89 (5), 76 (15).

L4 agent structure was confirmed using X-ray crystallography as depicted in Figure 4 and Table 2.

3.2.5 Synthesis of $N$-(3-((2,5-dichlorobenzyl)oxy)-4-(N-methylmethylsulfonamido)phenyl)-1naphthamide (L5)

White product, yield 80\%; m.p. 113-115 ${ }^{\circ} \mathrm{CIR}\left(\mathrm{cm}^{-1}\right)$ : $3298(\mathrm{NH}), 1741(\mathrm{CO}) ;{ }^{1} \mathrm{H} \mathrm{NMR}\left(\mathrm{CDCl}_{3}\right)$ : $\delta, \mathrm{ppm}=2.87\left(\mathrm{~s}, 3 \mathrm{H}, \mathrm{CH}_{3}\right), 3.27\left(\mathrm{~s}, 3 \mathrm{H}, \mathrm{CH}_{3}\right), 5.19\left(\mathrm{~s}, 2 \mathrm{H}, \mathrm{CH}_{2}\right), 6.99-7.99(\mathrm{~m}, 13 \mathrm{H}, \mathrm{Ar}-\mathrm{H}) 8.00$ (br, $1 \mathrm{H}, \mathrm{NH}, \mathrm{D}_{2} \mathrm{O}$ exchangeable); ${ }^{13} \mathrm{C} \mathrm{NMR}\left(\mathrm{CDCl}_{3}\right): \delta, \mathrm{ppm}=166.15,155.41,139.84,135.53$, $135.22,133.37,132.82,131.84,131.76,131.07,130.05,129.28$ (2C), 129.13, 128.36, 128.07, 127.95 (2C), $127.31,125.28,123.64,112.97,105.33,67.31,38.43,38.13 . \mathrm{C}_{26} \mathrm{H}_{23} \mathrm{Cl}_{2} \mathrm{~N}_{2} \mathrm{O}_{4} \mathrm{~S}$ MS: $m / z(\%)$, calculated 529.08; found, $528\left(\mathrm{M}^{+}, \mathrm{H}^{+}, 50\right), 449$ (70), $290(5), 155$ (100), $127(50)$. 


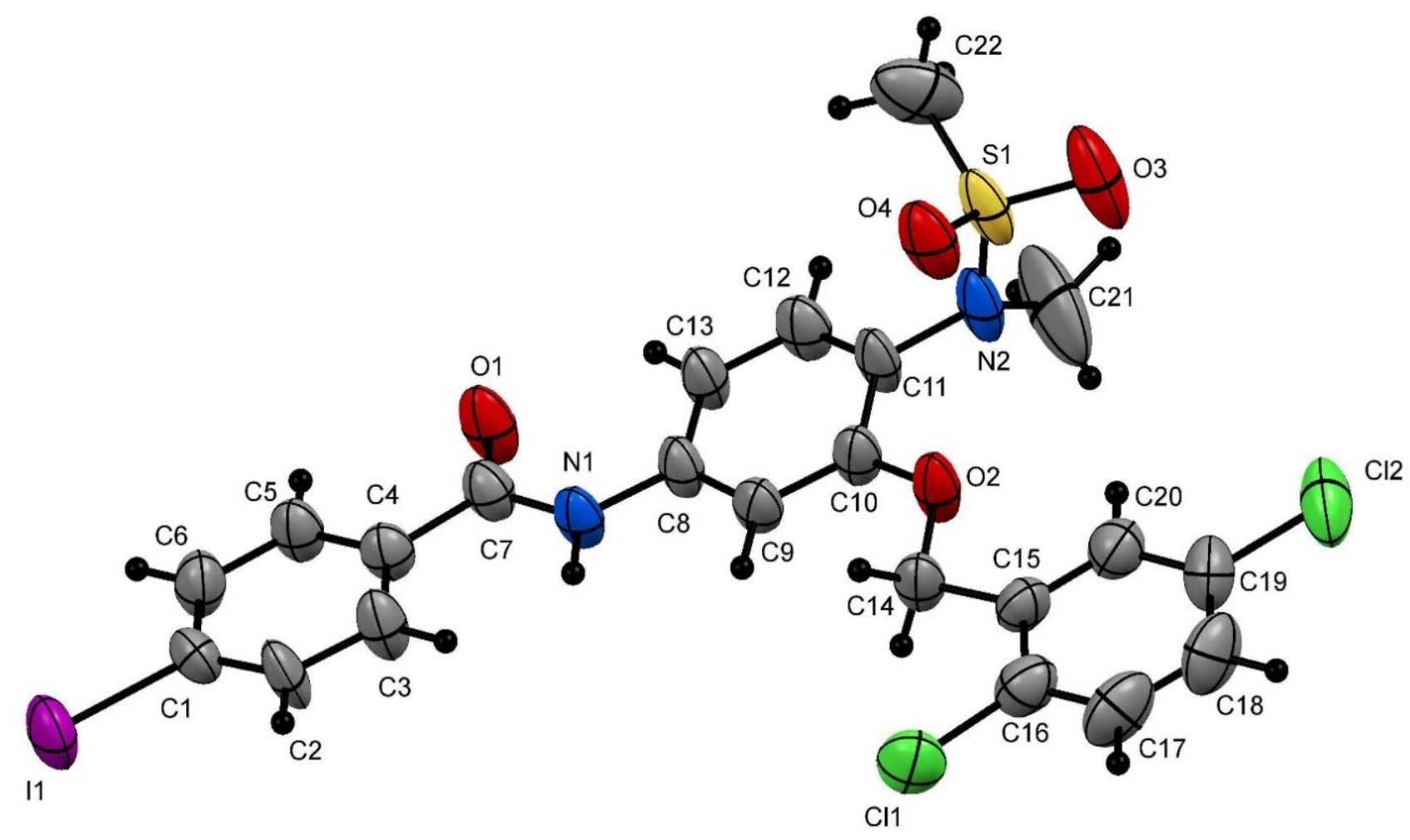

Figure 4: X-ray Single-crystal structure of agent $\mathrm{L} 4\left(\mathrm{C}_{22} \mathrm{H}_{19} \mathrm{Cl}_{2} \mathrm{IN}_{2} \mathrm{O}_{4} \mathrm{~S}\right)$.

Table 2

Crystallographic data for compound L4.

\begin{tabular}{|l|l|}
\hline Chemical formula & $\mathrm{C}_{22} \mathrm{H}_{19} \mathrm{Cl}_{2} \mathrm{IN}_{2} \mathrm{O}_{4} \mathrm{~S}$ \\
\hline Formula weight & 605.25 \\
\hline Wavelength & $0.71073 \AA$ \\
\hline Crystal size & $0.060 \times 0.150 \times 0.300 \mathrm{~mm}$ \\
\hline Crystal habit & clear colorless Block \\
\hline
\end{tabular}




\begin{tabular}{|c|c|}
\hline Crystal system & triclinic \\
\hline Space group & P -1 \\
\hline$a=8.194(14) \AA$ & $\alpha=97.20(7)^{\circ}$ \\
\hline$b=10.75(3) \AA$ & $\beta=100.12(4)^{\circ}$ \\
\hline$c=14.21(2) \AA$ & $\gamma=98.97(9)^{\circ}$ \\
\hline Volume & $1202 .(5) \AA^{3}$ \\
\hline $\mathbf{Z}$ & 2 \\
\hline Density (calculated) & $1.672 \mathrm{~g} / \mathrm{cm}^{3}$ \\
\hline Absorption coefficient & $1.672 \mathrm{~mm}^{-1}$ \\
\hline $\mathbf{F}(\mathbf{0 0 0})$ & 600 \\
\hline Volume & 1202.(5) $\AA^{3}$ \\
\hline Theta range for data collection & 1.47 to $24.92^{\circ}$ \\
\hline Index ranges & $-9<=\mathrm{h}<=9,-7<=\mathrm{k}<=12,-16<=\mathrm{l}<=16$ \\
\hline Reflections collected & 19197 \\
\hline Independent reflections & $4119[\mathrm{R}(\mathrm{int})=0.0714]$ \\
\hline Coverage of independent reflections & $98.3 \%$ \\
\hline Absorption correction & multi-scan \\
\hline Max. and min. transmission & 0.9063 and 0.6347 \\
\hline Structure solution technique & direct methods \\
\hline Structure solution program & SHELXS-97 (Sheldrick, 2008) \\
\hline Refinement method & Full-matrix least-squares on $\mathrm{F}^{2}$ \\
\hline Refinement program & SHELXL-97 (Sheldrick, 2008) \\
\hline Function minimized & $\Sigma \mathrm{w}\left(\mathrm{F}_{\mathrm{o}}^{2}-\mathrm{F}_{\mathrm{c}}^{2}\right)^{2}$ \\
\hline
\end{tabular}




\begin{tabular}{|l|l|}
\hline Data / restraints / parameters & $4119 / 0 / 291$ \\
\hline Goodness-of-fit on $\mathbf{F}^{2}$ & 1.041 \\
\hline $\mathbf{3 1 2 5}$ data; $\mathbf{I}>\mathbf{2} \sigma(\mathrm{I})$ & $\mathrm{R} 1=0.0844, \mathrm{wR} 2=0.2365$ \\
\hline all data & $\mathrm{R} 1=0.1059, \mathrm{wR} 2=0.2710$ \\
\hline Weighting scheme & $\mathrm{w}=1 /\left[\sigma^{2}\left(\mathrm{~F}_{\mathrm{o}}{ }^{2}\right)+(0.1702 \mathrm{P})^{2}+4.9574 \mathrm{P}\right]$ \\
\hline Absolute structure parameter & $\mathrm{where} \mathrm{P}=\left(\mathrm{F}_{\mathrm{o}}{ }^{2}+2 \mathrm{~F}_{\mathrm{c}}{ }^{2}\right) / 3$ \\
\hline Largest diff. peak and hole & $0.0(0)$ \\
\hline R.M.S. deviation from mean & 1.558 and $-1.659 \mathrm{e} \AA^{-3}$ \\
\hline
\end{tabular}


Table 3

Bond lengths and angles $(\AA)$ for agent $3\left(\mathrm{C}_{22} \mathrm{H}_{19} \mathrm{Cl}_{2} \mathrm{IN}_{2} \mathrm{O}_{4} \mathrm{~S}\right)$.

\begin{tabular}{llll}
\hline I1-C1 & $2.077(9)$ & $\mathrm{S} 1-\mathrm{O} 4$ & $1.426(8)$ \\
S1-O3 & $1.438(8)$ & $\mathrm{S} 1-\mathrm{N} 2$ & $1.626(11)$ \\
S1-C22 & $1.766(14)$ & $\mathrm{C} 11-\mathrm{C} 16$ & $1.729(12)$ \\
C12-C19 & $1.732(11)$ & $\mathrm{C} 4-\mathrm{C} 3$ & $1.360(13)$ \\
C4-C5 & $1.379(13)$ & $\mathrm{C} 4-\mathrm{C} 7$ & $1.521(12)$ \\
C6-C1 & $\mathrm{C} 6-\mathrm{C} 5$ & $1.413(13)$ \\
C1-C2 & $\mathrm{C} 2-\mathrm{C} 3$ & $1.380(13)$ \\
O1-C7 & $1.361(15)$ & $\mathrm{N} 1-\mathrm{C} 7$ & $1.359(12)$ \\
N1-C8 & $1.360(14)$ & $\mathrm{C} 13-\mathrm{C} 12$ & $1.373(13)$ \\
C13-C8 & $1.215(12)$ & $\mathrm{C} 9-\mathrm{C} 10$ & $1.380(13)$ \\
C9-C8 & $1.412(11)$ & $\mathrm{C} 10-\mathrm{O} 2$ & $1.351(12)$ \\
C10-C11 & $1.387(12)$ & $\mathrm{C} 12-\mathrm{C} 11$ & $1.352(14)$ \\
O2-C14 & $\mathrm{N} 2-\mathrm{C} 21$ & $1.405(17)$ \\
N2-C11 & $\mathrm{C} 14-\mathrm{C} 15$ & $1.517(13)$ \\
C16-C17 & $1.383(13)$ & $\mathrm{C} 16-\mathrm{C} 15$ & $1.381(14)$ \\
C20-C19 & $1.414(12)$ & $\mathrm{C} 20-\mathrm{C} 15$ & $1.376(14)$ \\
C17-C18 & $1.412(11)$ & $\mathrm{C} 18-\mathrm{C} 19$ & $1.382(17)$ \\
\hline
\end{tabular}

\begin{tabular}{|c|c|c|c|}
\hline O4-S1-O3 & $118.5(5)$ & O4-S1-N2 & $109.2(5)$ \\
\hline $\mathrm{O} 3-\mathrm{S} 1-\mathrm{N} 2$ & $106.9(6)$ & $\mathrm{O} 4-\mathrm{S} 1-\mathrm{C} 22$ & $105.6(7)$ \\
\hline $\mathrm{O} 3-\mathrm{S} 1-\mathrm{C} 22$ & $107.7(7)$ & $\mathrm{N} 2-\mathrm{S} 1-\mathrm{C} 22$ & $108.7(6)$ \\
\hline $\mathrm{C} 3-\mathrm{C} 4-\mathrm{C} 5$ & $120.3(9)$ & $\mathrm{C} 3-\mathrm{C} 4-\mathrm{C} 7$ & $123.8(8)$ \\
\hline $\mathrm{C} 5-\mathrm{C} 4-\mathrm{C} 7$ & $115.9(8)$ & $\mathrm{C} 1-\mathrm{C} 6-\mathrm{C} 5$ & $120.7(9)$ \\
\hline $\mathrm{C} 2-\mathrm{C} 1-\mathrm{C} 6$ & $118.9(8)$ & $\mathrm{C} 2-\mathrm{C} 1-\mathrm{I} 1$ & $120.5(7)$ \\
\hline C6-C1-I1 & $120.6(7)$ & $\mathrm{C} 1-\mathrm{C} 2-\mathrm{C} 3$ & $121.8(9)$ \\
\hline $\mathrm{C} 4-\mathrm{C} 3-\mathrm{C} 2$ & $119.6(9)$ & $\mathrm{C} 4-\mathrm{C} 5-\mathrm{C} 6$ & $118.7(8)$ \\
\hline C7-N1-C8 & $127.9(7)$ & $\mathrm{C} 12-\mathrm{C} 13-\mathrm{C} 8$ & $118.6(8)$ \\
\hline O1-C7-N1 & $123.1(8)$ & $\mathrm{O} 1-\mathrm{C} 7-\mathrm{C} 4$ & $121.3(8)$ \\
\hline N1-C7-C4 & $115.5(7)$ & $\mathrm{C} 10-\mathrm{C} 9-\mathrm{C} 8$ & $121.3(8)$ \\
\hline C9-C8-C13 & $119.4(8)$ & $\mathrm{C} 9-\mathrm{C} 8-\mathrm{N} 1$ & $116.4(7)$ \\
\hline C13-C8-N1 & $124.1(8)$ & $\mathrm{O} 2-\mathrm{C} 10-\mathrm{C} 9$ & $125.4(8)$ \\
\hline $\mathrm{O} 2-\mathrm{C} 10-\mathrm{C} 11$ & $115.8(8)$ & C9-C10-C11 & $118.8(8)$ \\
\hline $\mathrm{C} 11-\mathrm{C} 12-\mathrm{C} 13$ & $123.2(8)$ & $\mathrm{C} 10-\mathrm{O} 2-\mathrm{C} 14$ & $117.7(7)$ \\
\hline C21-N2-C11 & $119.6(11)$ & C21-N2-S1 & $119.1(10)$ \\
\hline C11-N2-S1 & $117.2(7)$ & $\mathrm{O} 2-\mathrm{C} 14-\mathrm{C} 15$ & $107.2(7)$ \\
\hline $\mathrm{C} 17-\mathrm{C} 16-\mathrm{C} 15$ & $121.5(11)$ & C17-C16-C11 & $118.6(9)$ \\
\hline $\mathrm{C} 15-\mathrm{C} 16-\mathrm{C} 11$ & $119.8(8)$ & $\mathrm{C} 19-\mathrm{C} 20-\mathrm{C} 15$ & $119.9(10)$ \\
\hline $\mathrm{C} 20-\mathrm{C} 15-\mathrm{C} 16$ & $118.5(9)$ & $\mathrm{C} 20-\mathrm{C} 15-\mathrm{C} 14$ & $121.4(8)$ \\
\hline C16-C15-C14 & $120.0(9)$ & C18-C17-C16 & $119.7(11)$ \\
\hline $\mathrm{C} 12-\mathrm{C} 11-\mathrm{C} 10$ & $118.4(8)$ & $\mathrm{C} 12-\mathrm{C} 11-\mathrm{N} 2$ & $122.4(8)$ \\
\hline $\mathrm{C} 10-\mathrm{C} 11-\mathrm{N} 2$ & $119.1(8)$ & $\mathrm{C} 17-\mathrm{C} 18-\mathrm{C} 19$ & $118.9(10)$ \\
\hline $\mathrm{C} 20-\mathrm{C} 19-\mathrm{C} 18$ & $121.5(10)$ & $\mathrm{C} 20-\mathrm{C} 19-\mathrm{Cl} 2$ & $119.6(9)$ \\
\hline $\mathrm{C} 18-\mathrm{C} 19-\mathrm{Cl} 2$ & $118.9(8)$ & & \\
\hline
\end{tabular}

\subsection{Biological studies}

\subsubsection{Cell lines and cell culture}

SKOV3 and SKBR3 cell lines, cell culture media, FBS, and MTT (3-(4,5-dimethylthiazol-2-yl)2,5-diphenyl-2H-tetrazolium bromide) were obtained from Sigma Aldrich. Women cancer cells were maintained in RPMI1640 medium containing 10\% fetal bovine serum (FBS), 2mmol/L L- 
glutamine, and 100U/mL penicillin-streptomycin and $100 \mu \mathrm{L}$ ciprofloxacin. FBS was heatinactivated for $30 \mathrm{~min}$ in a $37^{\circ} \mathrm{C}$ water bath before use. Cell cultures were grown at $37^{\circ} \mathrm{C}$, in a humidified atmosphere of $5 \% \mathrm{CO}_{2}$ in a $\mathrm{CO}_{2}$ incubator.

\subsubsection{MTT assay}

MTT assay was performed by monitoring the reduction of yellow MTT reagent to a blue product. Briefly, after culturing the cells in the monolayer cell culture plates, cells were harvested and then seeded with RPMI1640 medium into 96-well plate and incubated overnight. Then, cells were treated with different concentrations of anticancer agents in four replicates each and incubated for $72 \mathrm{~h}$. DMSO control wells received concentrations equal to those in the drug-treated cells. $100 \mu \mathrm{L}$ of $0.5 \mathrm{mg} / \mathrm{mL}$ of MTT reagent in fresh medium was added after the removal of the old medium. Then, cells were incubated in the $\mathrm{CO}_{2}$ incubator at $37^{\circ} \mathrm{C}$ for one hr. Supernatants were removed from the wells, and then $100 \mu \mathrm{L}$ DMSO were added on the reduced MTT dye. The final absorbency measurement was determined using a plate reader at $570 \mathrm{~nm}$ and the values were normalized to controls.

\subsubsection{Statistical analysis}

The cytotoxicity of the agents was determined using Graph Pad Prism software (Graph Pad Software Incorporated) and Microsoft Excel (Microsoft Corporation) was used to determine the statistical information. $\mathrm{IC}_{50}$ values were normalized using nonlinear regression analysis software.

\subsubsection{Western blot assay}

Confluent women cancer cells' dishes (SKOV3 and SKBR3) were washed with PBS and harvested by the scraper. The supernatants were then removed after centrifugation and the collected cell pellets were lysed by mixing them with RIPA, PI, and EDTA $150 \mu \mathrm{L}$. The cells were then vortexed and centrifuged for 60 minutes. Cell lysates were normalized using poly-acrylamide gel 
electrophoresis in the presence of $0.1 \%$ SDS. The gel contains the proteins that were transferred to the membrane followed by blocking with NFDM and PBST. The membrane was washed 3-4 times with PBST for 5 minutes. Then, the membrane was incubated with the primary antibody (target-HSP27, tubulin) for 24 hours. The next day the membrane was washed 3-4 times with PBST and incubated with the secondary antibody (horse radish peroxidase) for one hour. The membrane was again washed with PBST 3-4 times to be prepared for the visualization of the bands by chemiluminescence, and it was striped using B-actin.

\section{Conclusion}

In the present study, nimesulide analogues as dual tubulin and HSP27 inhibitor as anticancer agents were synthesized, and their structures are established by the chemical techniques. The developed nimesulide analogues can inhibit the function of tubulin and HSP27. Interestingly, MTT assay data revealed that both female cancer cell lines (SKOV3 and SKBR3) adapted cell growth inhibition. The present data indicated that nimesulide analogues have cytotoxic activity at micro molar concentration and promising as future chemotherapy drugs. The future goal is to synthesis new agents and improves their biological activities to reach the nano-molar level.

\section{Acknowledgments}

Research Sector Project Unit (RSPU) at Kuwait University- Faculty of Science is gratefully acknowledged including instrument project no: GS01/03, No: GS01/05, No: GS02/01, and No: GS 03/08.

\section{References}

1. Parker AL, Kavallaris M, McCarroll JA. Microtubules and their role in cellular stress in cancer. Front Oncol. 2014; 4:153. 
2. Bhalla, KN. Microtubule-targeted anticancer agents and apoptosis. Oncogene. 2003; 22:(56) 9075-86.

3. Fourest-Lieuvin, A; Peris, L; Gache, V. et al. Microtubule Regulation in Mitosis: Tubulin Phosphorylation by the Cyclin-dependent Kinase Cdk1. Mol Biol Cell. 2006; 17(3):10411050.

4. Jakob U, Gaestel M, Engel K, et al. Small heat shock proteins are molecular chaperones. $J$ Biol Chem. 1993; 268(3):1517-1520.

5. Rogalla T, Ehrnsperger M, Preville X, et al. Regulation of Hsp27 oligomerization, chaperone function, and protective activity against oxidative stress/tumor necrosis factor-alpha by phosphorylation. J Biol Chem. 1999; 274(27):18947-56.

6. Hansen RK, Parra I, Lemieux P, et al. Hsp27 overexpression inhibits doxorubicin-induced apoptosis in human breast cancer cells. Breast Cancer Res Treat. 1999; 56(2):187-16.

7. Nakashima M, Adachi S, Yasuda I, et al. Phosphorylation status of heat shock protein 27 plays a key role in gemcitabine-induced apoptosis of pancreatic cancer cells. Cancer Lett. 2011; 313(2):218-25.

8. Benndorf R, Hayess K, Ryazantsev S, et al. Phosphorylation and supramolecular organization of murine small heat shock protein HSP25 abolish its actin polymerizationinhibiting activity. J Biol Chem. 1994; 269(32):20780-4.

9. Guay J, Lambert H, Gingras-Breton G, et al. Regulation of actin filament dynamics by p38 map kinase-mediated phosphorylation of heat shock protein 27. J Cell Sci. 1997; 110(pt 3):357-38.

10. Huot J, Houle F, Spitz DR, et al. HSP27 phosphorylation-mediated resistance against actin fragmentation and cell death induced by oxidative stress. Cancer Res. 1996; 56(2):273-9 
11. Lelj-Garolla B, and Mauk AG. Self-association and chaperone activity of Hsp27 are thermally activated. J Biol Chem. 2006; 281(12):8169-74.

12. Gaestel M, Schroder W, Benndorf R, et al. Identification of the phosphorylation sites of the murine small heat shock protein hsp25. J Biol Chem. 1991; 266(22):14721-4.

13. Kang SH, Kang KW, Kim KH, et al. Upregulated HSP27 in human breast cancer cells reduces Herceptin susceptibility by increasing Her2 protein stability. BMC Cancer. 2008; 8:286.

14. Zhao L, Liu L, Wang S, et al. Differential proteomic analysis of human colorectal carcinoma cell lines metastasis-associated proteins. J Cancer Res Clin Oncol. 2007; 133(10):771-82.

15. Feng JT, Liu YK, Song HY, et al. Heat-shock protein 27: A potential biomarker for hepatocellular carcinoma identified by serum proteome analysis. Proteomics. 2005; 5(17):4581-8.

16. Wang A, Liu X, Sheng S, et al. Dysregulation of heat shock protein 27 expression in oral tongue squamous cell carcinoma. BMC Cancer. 2009; 9:167.

17. Kamada M, So A, Muramaki M, et al. Hsp27 knockdown using nucleotide-based therapies inhibit tumor growth and enhance chemotherapy in human bladder cancer cells. Molecular Cancer Therapeutics. 2007; 6(1):299-308.

18. Kase S, Parikh JG, Rao NA. Expression of heat shock protein 27 and alpha-crystallins in human retinoblastoma after chemoreduction. Br J Ophthalmol. 2009; 93(4):541-4.

19. Chatterjee S, Burns TF. Targeting Heat Shock Proteins in Cancer: A Promising Therapeutic Approach. Int J Mol Sci. 2017; 18(9):1978.

20. Jörg C, Sainitin V. Joachim H, et al. New HSP27 inhibitors efficiently suppress drug resistance development in cancer cells. Oncotarget. 2016; 7(42):68156-68169. 
21. Suman C, and Timothy F. Targeting Heat Shock Proteins in Cancer: A Promising Therapeutic Approach. Int J Mol Sci. 2017; 18(9):1978.

22. Jaragh-Alhadad L. In-vitro evaluation of HSP27 inhibitors function through HER2 pathway for ovarian cancer therapy. Transl Cancer Res. 2018,7(6):1510- 1517.

23. Zhong, B, Chennamaneni, S, Lama, R, et al. Synthesis and Anticancer Mechanism Investigation of Dual Hsp27 and Tubulin Inhibitors. J Med Chem. 2013; 56(13):5306-20.

24. Zhong, B, Lama, R, Kulman, DG, et al. Lead optimization of dual tubulin and Hsp27 inhibitors. European Journal of Medicinal Chemistry. 2014; 80:243-53.

25. Alhadad LJ, Harisa GI, Alanazi FK. Design and encapsulation of anticancer dual HSP27 and HER2 inhibitor into low-density lipoprotein to target ovarian cancer cells. Saudi Pharm J. 2020;28(4):387-396. doi:10.1016/j.jsps.2020.01.020

26. Hashemi Goradel N, Najafi M, Salehi E, Farhood B, Mortezaee K. Cyclooxygenase-2 in cancer: A review. J Cell Physiol. 2019;234(5):5683-5699. doi:10.1002/jcp.27411

27. Catarro M, Serrano JL, Ramos SS, Silvestre S, Almeida P. Nimesulide analogues: From antiinflammatory to antitumor agents. Bioorg Chem. 2019;88:102966. doi:10.1016/j.bioorg.2019.102966

28. Catarro M, Serrano J, Cavalheiro E, et al. Novel 4-acetamide-2-alkylthio-N-acetanilides resembling nimesulide: Synthesis, cell viability evaluation, and in silico studies. Bioorg Med Chem. 2017;25(16):4304-4313. doi:10.1016/j.bmc.2017.06.009

29. Čermák V, Dostál V, Jelínek M, et al. Microtubule-targeting agents and their impact on cancer treatment. Eur J Cell Biol. 2020;99(4):151075. doi:10.1016/j.ejcb.2020.151075 